\title{
Simulation Study and Parameter Evaluation on Water Level Control System of Steam Generator in Nuclear Power Plant
}

\author{
Chunyu $\mathrm{Bi}^{1}$ Pengfei Liu ${ }^{1, *}$, Xinli Song ${ }^{2}$, Guoyang $\mathrm{Wu}^{2}$ and Zhida $\mathrm{Su}^{2}$ \\ ${ }^{1}$ School of Nuclear Science and Engineering, Shanghai Jiao Tong University, Shanghai 200240, China \\ ${ }^{2}$ China Electric Power Institute, Beijing 100192, China \\ ${ }^{*}$ Corresponding author
}

\begin{abstract}
Based on a CPR1000 nuclear power plant simulation platform which is developed by Shanghai Jiao Tong University, simulation study and parameter evaluation on the water level control system of Steam Generator have been done in this paper. The response of the SG water level control system is validated by comparing with the design document of SG control system, which is simulated by CATIA2 Code. And then, the controller parameters of SG system are evaluated by Nichols chart and simulation platform. The simulation results show that this simulation platform has a good accordance with the CATIA2 and it can be used in the control system design of nuclear power plant
\end{abstract}

Keywords- nuclear power plant; SG water level control system; simulation; Nichols curve; parameter evaluation

\section{INTRODUCTION}

SG level control system, a kind of multi-input single-output system with the character of non-linearity and time varying, is one of the most complex systems in nuclear power plant. By traditional PID methods, it can hardly meet the requirements of SG water level transient control satisfactorily because of the existence of so-called "false water level". SG level control system is a hot topic in the research of nuclear power plant recently. In this paper, the SG level control system simulation study has been presented by a CPR1000 nuclear power plant simulation platform. CPR1000 reactor is a well-known reactor type in China and it has more than 10 commercial units. This paper mainly introduces two parts: (1) response of SG water level to feed-water flow, and (2) evaluation of water feed-water flow controller parameters in a CPR1000 nuclear power plant.

\section{SiMULATION PLATFORM DESCRIPTION}

\section{A. CPR1000 Simulation Platform}

A CPR1000 simulation platform has been developed by School of Nuclear Science and Engineering, Shanghai Jiao Tong University. The structure of this simulation platform had been shown in Figure 1. The main system thermal-hydraulic modules are developed by RELAP5, and it coupes with a 3D neutron kinetics module, which is used to simulate power distribution in the reactor. The I\&C system modules are developed by Matlab/Simulink, and Human Machine Interface is developed by DCS tool. Data communication between all the modules is based on a global database and network communication protocol. RELAP5 is a one-dimensional, unbalanced and two-phase thermal hydraulic system program developed by Idaho National Engineering Laboratory [1]. The program applies not only to nuclear reactor systems but also to non-nuclear reactor thermal hydrodynamic systems. Figure 2 shows thermal hydraulic nodalization scheme of the main loop of a CPR1000 type nuclear power plant in the simulation platform. It includes a reactor vessel, a pressurizer, three loops (which each has a steam generator and circulating pump) and other auxiliary systems. The secondary loop and other auxiliary systems are also presented in the simulation platform. This platform has been used in the verification and validation of the digital I\&C systems and reactor protection system in CPR1000 nuclear power plant, such as Ling Ao, Hong Yan He,Yang Jiang nuclear power plants[2-6]. When the simulation platform was used in the real nuclear power plant, the I\&C module can be replaced by the real control systems which were developed by the real DCS system, such as Siemens TXP+TXS.

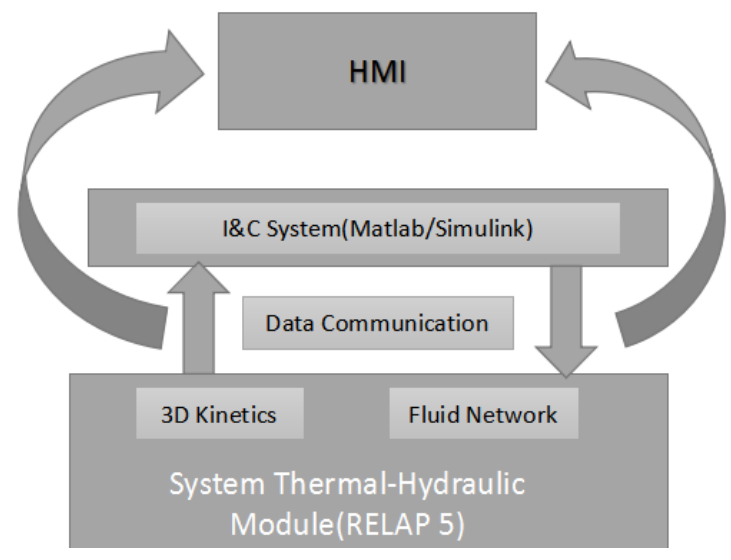

FIGURE I. STRUCTURE OF SIMULATION PLATFORM 


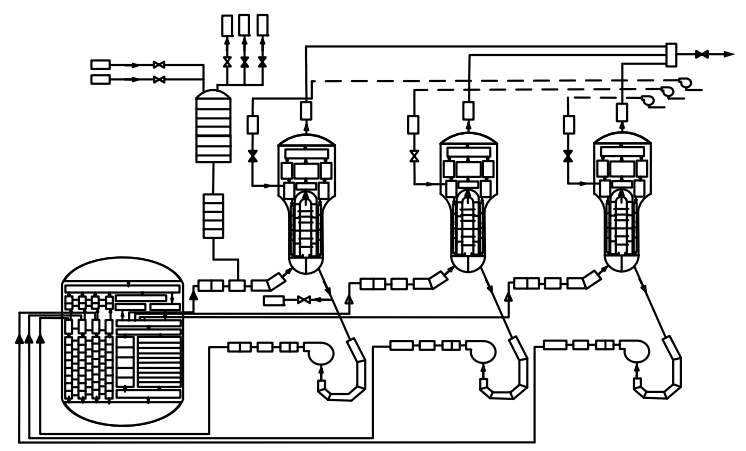

FIGURE II. NODALIZATION SCHEME OF THE NPP MAIN LOOP

\section{B. Parameter Evaluation Method}

The control system parameter will affect the static and dynamic characteristic of the control system. Parameter design and evaluation are also major research work in the control system design and debugging of the nuclear power plant. The controller parameters are evaluated by the simulation platform and MATLAB/Simulink with Nichols chart method in this paper. In a Nichols plot, the ordinate is the open loop logarithmic amplitude frequency characteristics, and the horizontal ordinate is the open loop phase frequency characteristic. Nichols plot generally includes the logarithmic amplitude-frequency characteristics of the open-loop transfer function and two sets of trajectories of equal amplitude $\mathrm{M}$ (unit: $\mathrm{dB}$ ) and equal phase (unit: degree). It is very easy to achieve gain margin and phase margin in the Nichols plot simultaneously. For a system, it is stable as long as the phase margin and the gain margin are positive. Additionally, the greater the margin, the more stable the system. However, the margin is not the bigger the better and the increasing of the margin may affect the dynamic performance of the system. Therefore, the parameters selected should satisfy the stability and dynamic performance of a system simultaneously.

\section{Simulation StUdy AND RESUlts ANALysis}

\section{A. Response of SG Water Level To Feed-Water Flow}

There is a balance between the feed-water flow and the steam mass flow during steady-state operation. Once there is a step change in feed-water flow, the water level will vary according to the integral of the difference between the feed water mass flow and the vapor mass flow due to the reduction in feed water over a long period of time. However, we will observe a "false water level" phenomenon in the short term. The water level initially decreases because of decrease of feed water load and increase of feed water subcooling, and then increase because of increase of steam pressure and more vapor condenses into water in the SG, finally decrease because of the differential of feed water flow and steam flow. The level dynamic performance does not meet the real requirement of SG level control system. This phenomenon also happens in the step change of steam flow. The transfer function that represents the response of the SG water level to feed-water flow is shown in the following Formula.

$$
S(s)=\frac{G_{1}}{s}-G_{3} \frac{1+\beta \tau s}{1+2 \varepsilon \tau s+\tau^{2} s^{2}}
$$

In the Formula $1, G_{1}$ is the system gain to the feed water flow, and $G_{3}$ is the system gain which is considering the influence of the feed water pump and feed water values.

The response of the SG water level to the feed-water flow step change is achieved by manually reducing the feed water flow by $5 \% \mathrm{FP}$ at different load levels (including 100\%FP, 90\% FP, $50 \% \mathrm{FP}, 30 \% \mathrm{FP}, 20 \% \mathrm{FP}, 10 \% \mathrm{FP}$ ), and then observe the changes in the water level of the SG over a period of time. Simulation results and designing document results are shown in Figure III and Figure IV.

It can be seen from Figure III and Figure 4 that the simulation results are basically the same as those in the design document. At the beginning, the water level decreases and then increase due to the existence of so-called "false water level". The more the load decreases, the more initial water level increases. In the end, the water level drops linearly due to the imbalance of feed-water flow. Step changes of steam flow have also been done in the research and the response of SG level is consistent between this simulation platform and CATIA2.

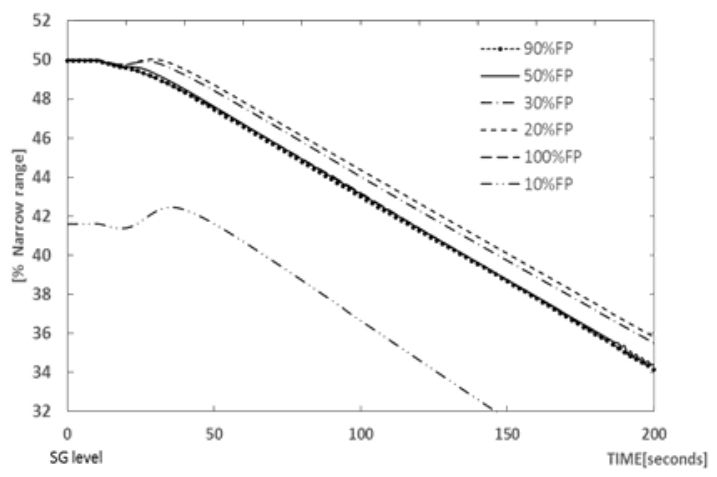

FIGURE III. RESPONSE OF SG LEVER TO A -5\% STEP OF FEEDWATER FLOW BY SIMULATION PLATFORM

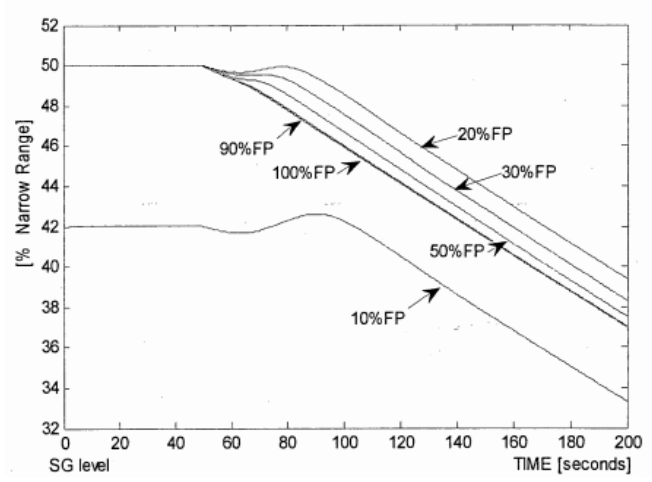

FIGURE IV. RESPONSE OF SG LEVER TO A -5\% STEP OF FEEDWATER FLOW BY CATIA2 


\section{B. Evaluation of Feed-water Flow Controller Parameters}

The water level of SG is an important operating parameter. It is related to many other parameters, such as feed water flow, feed water pressure, steam pressure difference, etc. These main parameters are controlled by corresponding controllers. SG water level control principle is shown in Figure V. In this section, feed-water flow controller will be studied as an example.

The feed-water flow controller is a proportional integral which values $\mathrm{K}(1+1 / \mathrm{Ts})$.In the design of Ling Ao Phase II nuclear power plant, $\mathrm{K}=0.33 \%$ opening $/ \%$ feed water flow and $\mathrm{T}=5 \mathrm{~s}$. The transfer function of the feed-water flow control is:

$$
\begin{aligned}
S(s) & =e^{-0.5 s} \frac{1}{1+2 \frac{1.028}{3.112} s+\frac{s^{2}}{3.112^{2}}}\left(\frac{0.125}{0.214 s+1}+\frac{0.4221}{\frac{1}{0.2249^{2}} s^{2}+2 \frac{0.7953}{0.2249} s+1}\right) \\
& * K\left(1+\frac{1}{T S}\right)
\end{aligned}
$$

The main content of this experiment is to study the different value of the gain margin and phase margin when changing the value of the gain $\mathrm{K}$ and the integration time constant $\mathrm{T}$. And then, it is determined whether the actual value of nuclear power plant is appropriate combined with flow rate changes in the closed-loop response. When the value of $\mathrm{K}$ is set to $\mathrm{K}=0.33 \%$ opening $/ \%$ feed water and the values of $\mathrm{T}$ are $2 \mathrm{~s}, 3 \mathrm{~s}, 5 \mathrm{~s}, 6 \mathrm{~s}$ respectively, the Nichols plot gained corresponding to transfer function are shown in Figure VI. The gain margin and phase margin obtained are shown in Table I.

When the value of $\mathrm{T}$ is set to $5 \mathrm{~s}$ and the value of $\mathrm{K}$ is $\mathrm{K}=$ $0.2 \%$ opening $/ \%$ feed water, $\mathrm{K}=0.33 \%$ opening $/ \%$ feed water, $\mathrm{K}=0.5 \%$ opening $/ \%$ feed water respectively, the Nichols plot gained corresponding to transfer function are shown in Figure VII. The gain results obtained are as shown in Table II.

Results of Table I and Table II can be concluded as follows:

- The phase margin increases as the integration time constant increases, however it hardly changes as the controller gain increases;

- The gain margin decreases as the controller gain increases, however it hardly changes as the time constant increases.

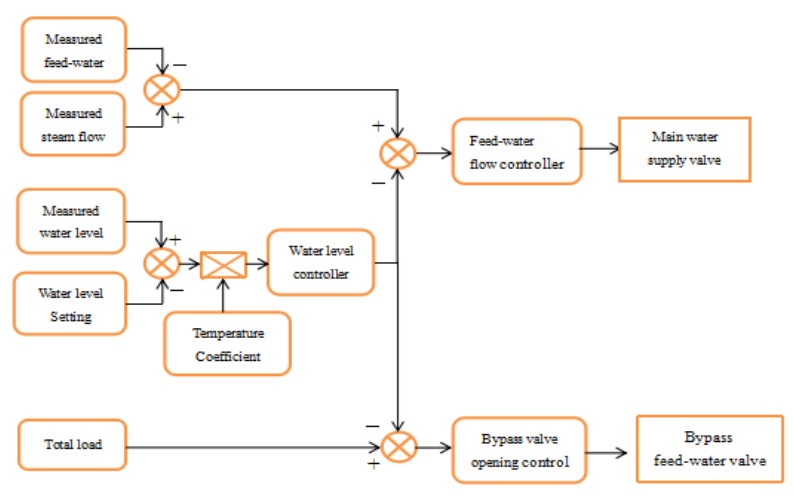

FIGURE V. SG WATER LEVEL CONTROL PRINCIPLE

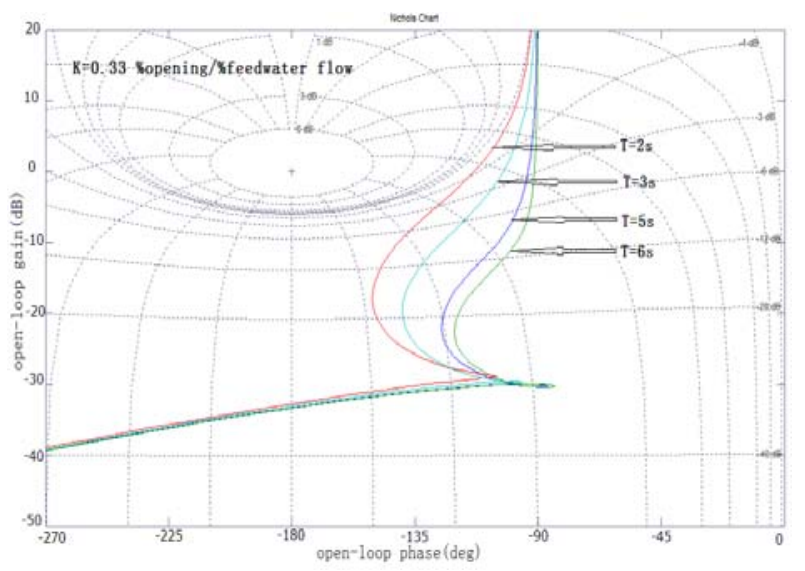

FIGURE VI. NICHOLS PLOT OF THE FEED-WATER FLOW CONTROLLER WITH DIFFERENT INTEGRAL TIME CONSTANT $\mathrm{T}$

TABLE I. GAIN MARGIN AND PHASE MARGIN OF FEED-WATER FLOW CONTROLLER WITH DIFFERENT T

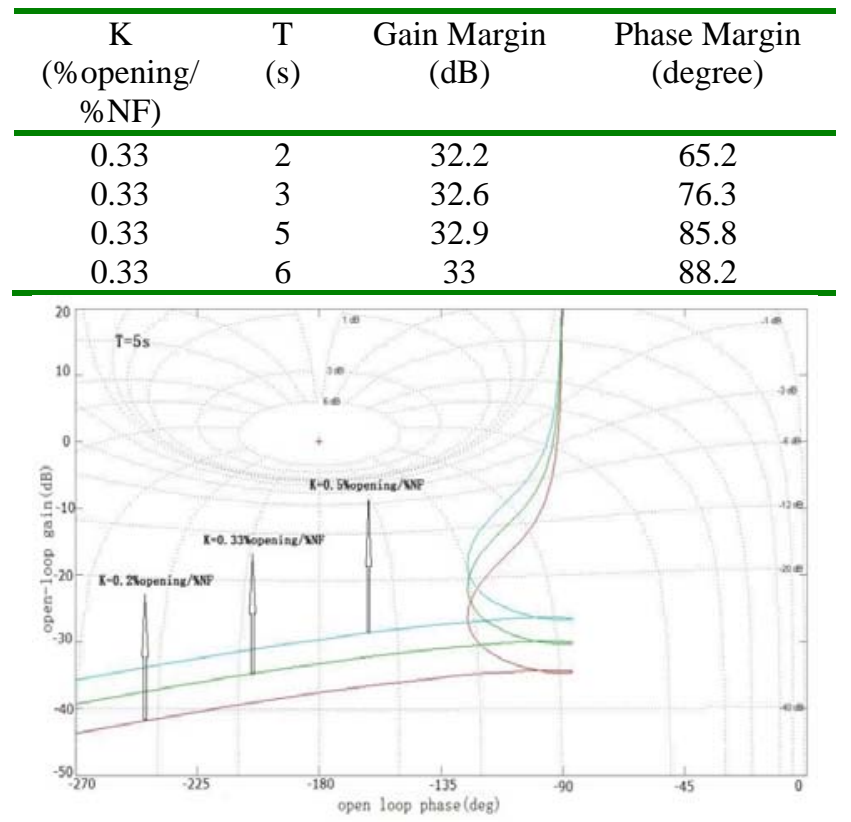

FIGURE VII. NICHOLS PLOT OF FEED-WATER FLOW CONTROLLER WITH DIFFERENT GAIN K

Therefore, to maintain the stability of the controller, a smaller controller gain and a larger integration time constant are required. However, these may affect the dynamic performance of the control system.

The closed-loop responses of the control system under the conditions of the step change of the feed-water flow, 100\% FP and two electric feed-water pump automatic operation mode are shown in Figure VIII and Figure IX. 
TABLE II. GAIN MARGIN AND PHASE MARGIN OF FEED-WATER FLOW CONTROLLER WITH DIFFERENT GAIN K

\begin{tabular}{cccc}
\hline $\begin{array}{c}\mathrm{K} \\
\text { (\%opening/ } \\
\text { \%NF) }\end{array}$ & $\begin{array}{c}\mathrm{T} \\
(\mathrm{s})\end{array}$ & $\begin{array}{c}\text { Gain Margin } \\
(\mathrm{dB})\end{array}$ & $\begin{array}{c}\text { Phase Margin } \\
\text { (degree) }\end{array}$ \\
\hline 0.2 & 5 & 37.3 & 87.5 \\
0.33 & 5 & 32.9 & 85.8 \\
0.5 & 5 & 29.3 & 83.3 \\
\hline
\end{tabular}

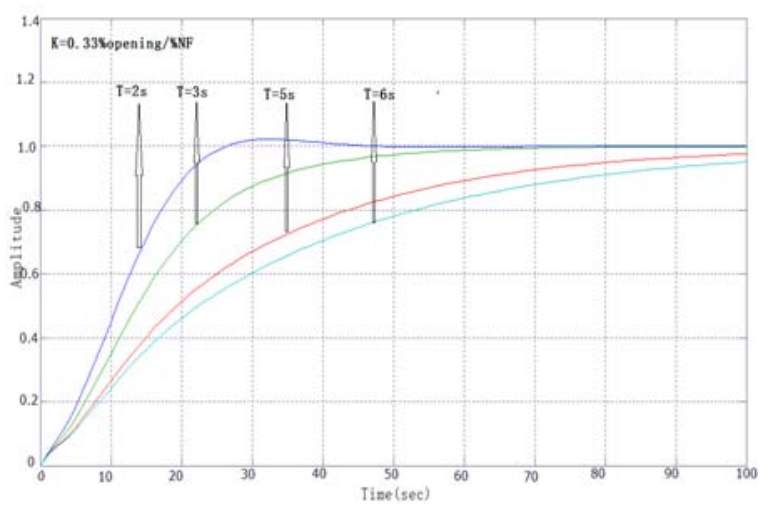

FIGURE VIII. THE CLOSED-LOOP RESPONSES AT THE STEP CHANGE OF THE FEED-WATER FLOW WITH DIFFERENT T

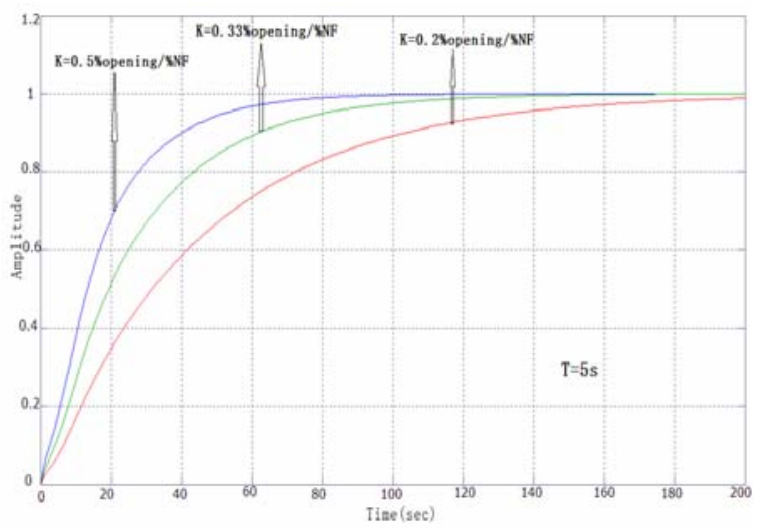

FIGURE IX. THE CLOSED-LOOP RESPONSES AT THE STEP CHANGE OF THE FEED-WATER FLOW WITH DIFFERENT K

From Figure VIII and Figure IX, it can be concluded that the larger the integral time constant or the smaller the controller gain is, the greater the resistance and the smaller the response time will be achieved. Therefore, in order to improve the closed-loop response of the control channel, a smaller controller integration time and a large controller gain are appropriate.

Therefore, in the design of in Ling Ao Phase II nuclear power plant, $\mathrm{K}=0.33 \%$ opening $/ \%$ feed water flow and $\mathrm{T}=5 \mathrm{~s}$ is the best optimal value. This option takes into account both the stability and the closed-loop response time requirements. Parameters evaluation of level controller and pressure differential controller of steam and feed-water have also been done in this research.

\section{CONCLUSION}

This paper establishes a method to simulate and evaluate the steam generator water level control system. The performance curves and controller parameters of the SG water level control system of Ling Ao Phase II nuclear power plant are simulated and evaluated by using the CPR1000 simulation platform and Matlab / Simulink software. Compared with the design document of nuclear power plant, the response of SG lever to a $-5 \%$ step of feed-water flow obtained by simulation platform is basically consistent. The selection of the parameters of the feed-water flow controller by the platform arrives at the same conclusion with the design document of nuclear power plant for that meets the requirement of control. The research results show that this simulation platform can be used in the control system design of the CPR1000 type nuclear power plant.

\section{ACKNOWLEDGMENT}

Authors are grateful to State Grid Corporation Science and Technology Project (No: XT71-15-060) of China and China Electric Power Research Institute Innovation Fund Project (No: XT83-15-002) for providing the financial support for this study.

\section{REFERENCES}

[1] The RELAP5 Code Development Team. SCDAP/RELAP5/MOD3.2 Code Manual[M]. USA: Idaho National Engineering Laboratory, 1995.

[2] P. Liu, M. Lin, and D. Hou, "Research on engineering eimulator for function validating of DCS in nuclear power plant," Nuclear Power Engineering,30(5s),48-51, pp.2009.

[3] M. Lin, Y. Su, and R. Hu, "Development of a thermal-hydraulic system code for simulators based on RELAP5 code,” Nucl. Eng. Des. 235 (6), pp. 675-686, 2005.

[4] M. Lin, D. Hou, and P. Liu, "Main control system verification and validation of NPP digital I\&C system based on engineering simulator," Nucl. Eng. Des. 240 , pp. 1887-1896, 2010.

[5] D. Hou, M. Lin, and Z. Xu, "Development and application of an extensible engineering simulator for NPP DCS closed-loop test,” Annals of Nuclear Energy, pp. 38, 49-5, 2011.

[6] Y. Li, M.Lin, Y. Yang, "Coupling methods for parallel running RELAPSim codes in nuclear power plant simulation," Nucl. Eng. Des. ,297, pp. 1-14,2016 